\title{
Protocol for measuring myocardial blood flow by PET/CT in cats
}

\author{
Simone D. Jenni • Tiziano Schepis • Rolf Jenni • \\ Patrick T. Siegrist • Philipp A. Kaufmann • \\ Tony M. Glaus
}

Received: 14 May 2008 / Accepted: 19 August 2008 / Published online: 26 September 2008

(C) Springer-Verlag 2008

\begin{abstract}
Purpose The aim of this study was to establish a protocol for measuring myocardial blood flow (MBF) by PET/CT in healthy cats. The rationale was its future use in Maine Coon cats with hypertrophic cardiomyopathy (HCM) as a model for human HCM.

Methods MBF was measured in nine anaesthetized healthy cats using a PET/CT scanner and ${ }^{13} \mathrm{NH}_{3}$ at rest and during adenosine infusion. Each cat was randomly assigned to receive vasodilator stress with two or three adenosine infusions at the following rates $(\mu \mathrm{g} / \mathrm{kg}$ per minute): 140 (Ado 1, standard rate for humans), 280 (Ado 2, twice the human standard rate), 560 (Ado 4), 840 (Ado 6) and 1,120 (Ado 8).

Results The median MBF at rest was $1.26 \mathrm{ml} / \mathrm{min}$ per $\mathrm{g}$ $(n=9$; range $0.88-1.72 \mathrm{ml} / \mathrm{min}$ per $\mathrm{g}$ ). There was no
\end{abstract}

S. D. Jenni · T. M. Glaus

Division of Cardiology,

Clinic for Small Animal Internal Medicine,

Vetsuisse Faculty, University of Zurich,

Winterthurerstrasse 260,

CH-8057 Zurich, Switzerland

T. Schepis $\cdot$ P. T. Siegrist $\cdot$ P. A. Kaufmann $(\bowtie)$

Cardiovascular Center, Nuclear Cardiology,

University Hospital Zurich,

NUK C 42, Rämistrasse 100,

CH-8091 Zurich, Switzerland

e-mail:pak@usz.ch

R. Jenni

Cardiovascular Center, Echocardiography, University Hospital,

Zurich, Switzerland

P. A. Kaufmann

Zurich Center for Integrative Human Physiology,

University of Zurich,

Zurich, Switzerland significant difference at Ado $1(n=3$; median 1.35, range $0.93-1.55 \mathrm{ml} / \mathrm{min}$ per $\mathrm{g}$; ns) but MBF was significantly greater at Ado $2(n=6 ; 2.16$, range $1.35-2.68 \mathrm{ml} / \mathrm{min}$ per g; $p<0.05)$ and Ado $4(n=6 ; 2.11,1.92-2.45 \mathrm{ml} / \mathrm{min}$ per $\mathrm{g} ; p<$ 0.05). Large ranges of MBF values at Ado $6(n=4 ; 2.53$, $2.32-5.63 \mathrm{ml} / \mathrm{min}$ per $\mathrm{g}$; ns) and Ado $8(n=3 ; 2.21,1.92$ $5.70 \mathrm{ml} / \mathrm{min}$ per $\mathrm{g}$; ns) were noted. Observed adverse effects, including hypotension, AV-block and ventricular premature contractions, were all mild, of short duration and immediately reversed after cessation of the adenosine infusion.

Conclusion MBF can be safely measured in cats using PET. An intravenous adenosine infusion at a rate of $280 \mu \mathrm{g} / \mathrm{kg}$ per minute seems most appropriate to induce maximal hyperaemic MBF response in healthy cats. Higher adenosine rates appear less suitable as they are associated with a large heterogeneity in flow increase and rate pressure product, most probably due to the large variability in haemodynamic and heart rate response.

Keywords PET $\cdot$ Myocardial blood flow $\cdot$ Cats

\section{Introduction}

Myocardial blood flow (MBF) can be measured in humans non-invasively and accurately using PET and ${ }^{15} \mathrm{O}$-radiolabelled water or ${ }^{13} \mathrm{~N}$-radiolabelled ammonia at rest and in response to several stimuli, such as adenosine, bicycle exercise, dobutamine and the cold pressor test [1-4].

Myocardial perfusion reserve (MPR), the ratio of MBF during coronary vasodilation to basal MBF, is an integrated measure of flow through both the large epicardial coronary arteries and the microcirculation, and has been proposed as an indirect parameter to evaluate the function of the 
coronary circulation $[3,5]$. An abnormal MPR can be due to narrowing of the epicardial coronary arteries [6] or, in the absence of angiographically demonstrable atherosclerotic disease, may reflect dysfunction of the coronary microcirculation [7-11]. In fact, PET is particularly helpful in circumstances where the MPR is diffusely blunted due to a widespread abnormality of the coronary microcirculation, such as in hypertrophic cardiomyopathy $(\mathrm{HCM})[7$, $12,13]$.

HCM is the most common cause of sudden cardiac death in the young as well as a major cause of morbidity and mortality in the elderly [14]. Interestingly, HCM is also the most common cardiac disease in domestic cats and mutations in the feline MYBPC3 have recently been shown to cause familial HCM [15] in Maine Coon and Ragdoll cats [16]. Feline familial HCM thus mimics the hereditary aspects, phenotypic expression, natural history and pathological characteristics of the human familial form of the disease [17], making these cats an ideal model for studying the coronary circulation in HCM.

Unfortunately, there is no standardized protocol to assess MPR in cats and maximal hyperaemic MBF values in cats are unknown. Only scant data exist on the effects of adenosine infusion on feline hearts. In isolated perfused cat hearts adenosine infusion at $2 \mu \mathrm{g} / \mathrm{g}$ heart wet weight per minute increases left ventricular pressure, heart rate and coronary conductance (coronary flow/perfusion pressure) [18]. In pressure-overloaded feline hearts an elevated MBF has been found with adenosine infusion at a constant rate of $0.543 \mu \mathrm{g} / \mathrm{kg}$ per minute over $7 \mathrm{~min}$ using the carbonized microsphere method [19]. Nevertheless, maximal hyperaemic MBF in cats remains unknown.

Thus, the purpose of this study was to establish a protocol to determine resting and hyperaemic MBF and MPR by PET in healthy cats for future reference in cats with HCM. Emphasis was placed on the adenosine dose necessary to produce maximal $\mathrm{MBF}$ and its adverse effects.

\section{Materials and methods}

Animals

Nine healthy cats (six Maine Coon cats from a private breeder, two laboratory cats and one European domestic short-hair cat from a private owner) were included in the study. The two laboratory cats were used at the beginning of the study for more invasive cardiovascular monitoring.

None of the cats used had a history of cardiac disease and all were judged to be healthy based on clinical examination, echocardiography and blood examination. Their weight range was $3.7-10.5 \mathrm{~kg}$ (median $4.7 \mathrm{~kg}$ ), their age range was 7-75 months (median 16 months), and there were six male and three female cats. All examinations were performed with written permission of the Federal Veterinary Office, Secretariat of Animal Research, Zurich, Switzerland.

\section{Anaesthesia}

The cats were sedated with intramuscular buprenorphine (Temgesic; Essex Chemie, Luzern, Switzerland) $0.003 \mathrm{mg} / \mathrm{kg}$ and acepromazine (Prequillan; Arovet, Zollikon-Station, Switzerland) $0.01 \mathrm{mg} / \mathrm{kg}$. Anaesthesia was induced $20 \mathrm{~min}$ later with propofol (Propofol 1\%; Fresenius, Stans, Switzerland) $2-5 \mathrm{mg} / \mathrm{kg}$ intravenously (i.v.) and sustained with isoflurane and oxygen inhalation.

\section{Monitoring}

In all cats heart rate, respiratory rate, oxygen saturation, and electrocardiogram (ECG) were continuously monitored. Additionally, in two laboratory cats direct arterial blood pressure (BP) was continuously measured with a catheter in the right femoral artery, and in two other cats indirect arterial BP was noninvasively measured at the right femoral artery. All measurements were done with a Cardiocap/5 system (Datex-Ohmeda Division, Finland).

\section{PET}

PET studies were performed using a whole-body scanner (Discovery LS PET/CT scanner; GE Healthcare, Milwaukee, WI), which is an integration of an Advance NXi PET scanner, which records 35 image planes simultaneously, with a LightSpeed plus multislice helical CT scanner. The axial field of view was $14.5 \mathrm{~cm}$. Correct positioning of the cat's heart within the axial field of view of the tomograph was confirmed on a rectilinear transmission scan (Fig. 1). This CT scan was also used for photon attenuation correction as previously described [20]. All scans were performed using ${ }^{13} \mathrm{~N}$-labelled ammonia (350-400 MBq). Starting with the i.v. administration of the tracer into the cephalic vein, nine frames of $10 \mathrm{~s}$, six frames of $15 \mathrm{~s}$, two frames of $30 \mathrm{~s}$, one frame of $60 \mathrm{~s}$, and one frame of $900 \mathrm{~s}$ were recorded [13].

MBF was measured at rest followed by serial measurements during adenosine-induced hyperaemia at intervals of 50 min to allow for decay of ${ }^{13} \mathrm{~N}$.

\section{Study protocol}

Adenosine was administered as a continuous rate infusion, which was started 3 min before injection of the tracer and continued for 4 min more. In the pilot study (one cat) the 
a

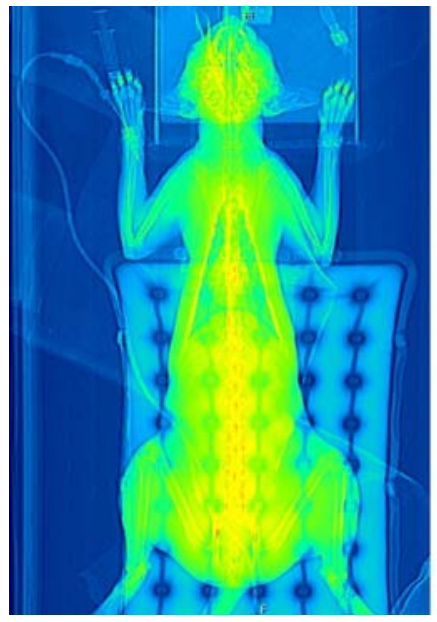

b

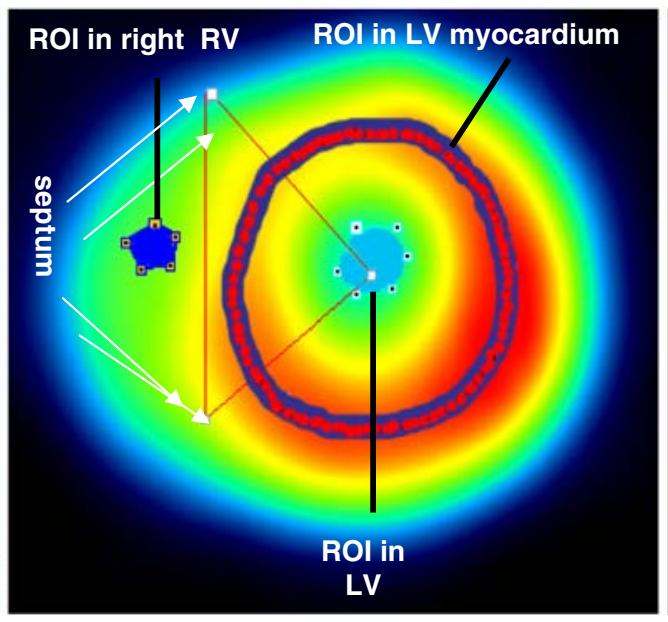

C

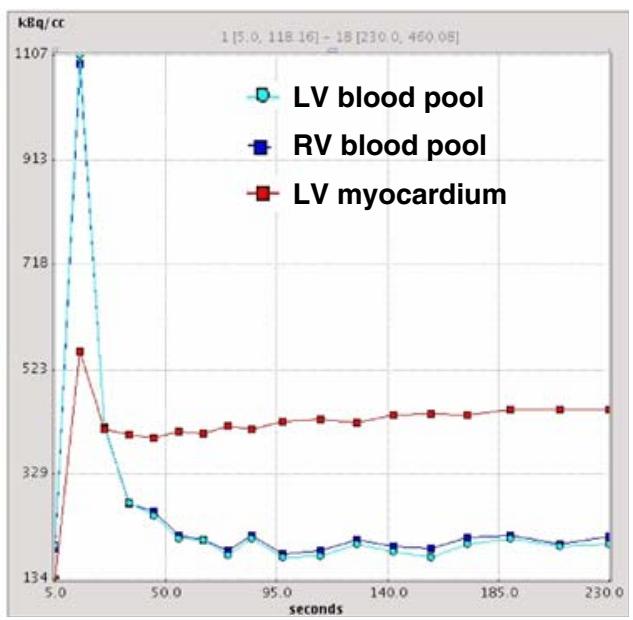

Fig. 1 a CT transmission scan of intubated cat. b ROIs on the left and right ventricular cavities and myocardial tissue drawn on a short axis slice of the heart. c Time-activity curves of left ventricular (LV) blood pool (input function), right ventricular (RV) blood pool, and LV myocardium

adenosine dose chosen for hyperaemic MBF measurement was the human standard rate of $140 \mu \mathrm{g} / \mathrm{kg}$ per minute (Ado 1). The remaining cats received two $(n=3)$ or three $(n=5)$ different adenosine doses. The adenosine doses chosen were the human standard dose (Ado 1, n=3), twice the human standard dose (Ado 2, $280 \mu \mathrm{g} / \mathrm{kg}$ per minute, $n=$ 6), four times the human standard dose (Ado $4,560 \mu \mathrm{g} / \mathrm{kg}$ per minute, $n=6)$, six times the human standard dose (Ado $6,840 \mu \mathrm{g} / \mathrm{kg}$ per minute, $n=4$ ), and eight times the human standard dose (Ado $8,1,120 \mu \mathrm{g} / \mathrm{kg}$ per minute, $n=$ $3)$. The doses and their sequence of administration in individual cats were randomly assigned.

\section{Estimates of myocardial blood flow}

Transaxially acquired images were reoriented to obtain short axis images of the heart. A basal, a midventricular, and an apical slice were then chosen for further analysis. In each slice a region of interest (ROI) was placed within the septal, anterior, lateral, and inferior segments. A spherical ROI was placed in the blood pool of the left ventricle (Fig. 1). Myocardial and blood pool time-activity curves were generated from the dynamic frames and corrected for radioisotope decay. MBF was estimated by model fitting of the blood pool and myocardial time-activity curves [21]. Partial volume and spillover (both accounting for the resolution distortion) were corrected as previously reported $[11,13,22]$ using the method developed [23] and validated [24] by Hutchins et al. MPR was calculated as the ratio of hyperaemic to resting MBF values [10, 13, 22]. Under normal conditions, myocardial oxygen consumption is linearly related to the heart rate-BP product (RPP), an index of external cardiac work, and both are related to coronary blood flow [9]. To allow meaningful interpretation of the quantitative data, it has been proposed that resting MBF be corrected for RPP. In view of the median RPP value of 15,000 under anaesthesia at rest in the present study, it seemed appropriate to use this value for normalization. In addition, to account for the variability of coronary driving pressure, coronary resistance $\left(\mathrm{mmHg} \times \min \times \mathrm{g} \times \mathrm{ml}^{-1}\right)$ was also calculated as the ratio of mean arterial pressure (MAP) to MBF [9].

\section{Statistical analysis}

Values are given as medians and range, as no normal distribution could be assumed due to lack of previous empirical data. Differences in hyperaemic MBF at various adenosine doses as well as correlations between adenosine dose and MBF were calculated using nonparametric methods and a commercial statistical software solution (SPSS, Statistical Package for the Social Sciences, software for Windows, version 11). $P$ values $<0.05$ were considered statistically significant.

\section{Results}

Haemodynamics and physiological data

Heart rate was constant (median 155, range 113-188 beats/ min) throughout 17 of 22 PET scans with adenosine. In five scans, heart rate markedly increased (by a median of 30 , range $20-80$ beats $/ \mathrm{min}$ ) during adenosine infusion (Table 1).

MAP decreased from $89 \mathrm{mmHg}$ at baseline to $56 \mathrm{mmHg}$ and to $61 \mathrm{mmHg}$ during adenosine infusion at Ado 2 and Ado 6, respectively, and returned to baseline within $1 \mathrm{~min}$ after the end of the infusion in one cat with invasive BP 
Table 1 Haemodynamics

\begin{tabular}{llllll}
\hline & At rest & Ado 1 & Ado 2 & Ado 4 & Ado 6 \\
\hline Blood pressure (mmHg) & & & & & \\
Systolic & 109 & 128 & 109 & 96 & 88 \\
Diastolic & 58 & 58 & 44 & 42 & 42 \\
Mean & 83 & 81 & 72 & 66 & 63 \\
Heart rate (beats/min) & 142 & 161 & 155 & 147 & 79 \\
Rate-pressure product & 15,478 & 20,608 & 16,895 & 14,112 & 137,816 \\
\hline
\end{tabular}

In normal anaesthetized cats maintained with isoflurane inhalation, heart rate is $184 \pm 28$ beats/min and blood pressure values are systolic $110 \pm$ $19 \mathrm{mmHg}$, diastolic $72 \pm 17 \mathrm{mmHg}$ and mean $85 \pm 17 \mathrm{mmHg}$, resulting in a calculated RPP of 20,240 [29].

measurement. In this cat during adenosine infusion at Ado 2, heart rate increased from 136 to 159 beats $/ \mathrm{min}$, and during infusion at Ado 6 heart rate increased from 136 to 186 beats/min. In the second cat with invasive BP monitoring there was no relevant decrease in MAP with adenosine infusion at Ado 4 or Ado 8. With infusion at Ado 8 , this cat seemed to be waking up from anaesthesia showing palpebral reflex activity associated with a rise in heart rate from 159 to 172 beats/min, which returned to baseline after stopping the adenosine infusion.

In one cat with indirect BP measurement calculated MAP decreased from $75 \mathrm{mmHg}$ at baseline to 41,50 and $60 \mathrm{mmHg}$ with adenosine infusion at Ado 8, Ado 6 and Ado 2, respectively, returning to baseline within 1-3 min at the end of the infusions. With the highest adenosine dose, heart rate increased from 138 to 172 beats $/ \mathrm{min}$. In the other cat with noninvasive monitoring there was no relevant MAP decrease or heart rate increase with infusion at Ado 6, Ado 4 or Ado 2.

ECG abnormalities occurred in three cats, all during adenosine infusion at Ado 4, consisting of singular monofocal ventricular premature contractions (VPCs), a single short episode of second degree 3:1 AV-block, and an episodic second degree AV-block. Subsequently, at higher doses of adenosine (Ado 6 and Ado 8) no ECG abnormalities were detected in any of the cats. Respiratory rate at $17-21$ breaths per minute and oxygen saturation above $94 \%$ remained stable throughout the study in all scans.

\section{Myocardial blood flow and perfusion reserve}

Median MBF was $1.26 \mathrm{ml} / \mathrm{min}$ per $\mathrm{g}(n=9$; range 0.88 $1.72 \mathrm{ml} / \mathrm{min}$ per g) with minimal change after correction for RPP (median 1.59, range $1.16-1.72 \mathrm{ml} / \mathrm{min}$ per g) indicating comparable haemodynamic conditions. There was no significant change at Ado $1 \quad(n=3$; median 1.35, range $0.93-1.55 \mathrm{ml} / \mathrm{min}$ per g; ns) but a significant increase at Ado 2 ( $n=6$; median 2.16, range $1.35-2.68 \mathrm{ml} / \mathrm{min}$ per g; $p<0.05)$ and Ado $4(n=6$; median 2.11 , range 1.92 $2.45 \mathrm{ml} / \mathrm{min}$ per $\mathrm{g} ; p<0.05)$. A large range of $\mathrm{MBF}$ response was noted at Ado $6(n=4$; median 2.53, range
$2.32-5.63 \mathrm{ml} / \mathrm{min}$ per g; ns) and Ado $8(n=3$; median 2.21 , range $1.92-5.70 \mathrm{ml} / \mathrm{min}$ per $\mathrm{g}$; $\mathrm{ns})$. Interestingly, at the highest rates, the MBF response was declining again in some cats (Fig. 2).

Median MPR was 1.42 (range 1.05-1.74) at Ado 1, 1.65 (range 1.22-2.30) at Ado 2, 1.54 (range 1.50-2.19) at Ado 4, 1.92 (range 1.35-6.39) at Ado 6, and 1.90 (range 1.20-4.13) at Ado 8. Consequently, the coronary resistance decreased from $66 \mathrm{mmHg} \times \min \times \mathrm{g} \times \mathrm{ml}^{-1}$ at rest to 60,33 , 31, 24 and $36 \mathrm{mmHg} \times \min \times \mathrm{g} \times \mathrm{ml}^{-1}$ at Ado 1, Ado 2, Ado 4, Ado 6 and Ado 8, respectively.

\section{Discussion}

Our study showed that MBF can be measured in cats by PET with ${ }^{13} \mathrm{NH}_{3}$ as flow tracer. MBF can be manipulated in cats by adenosine infusion. A primary goal of this study was to establish the ideal adenosine dose for obtaining the MPR in cats. The ideal dose would consistently result in

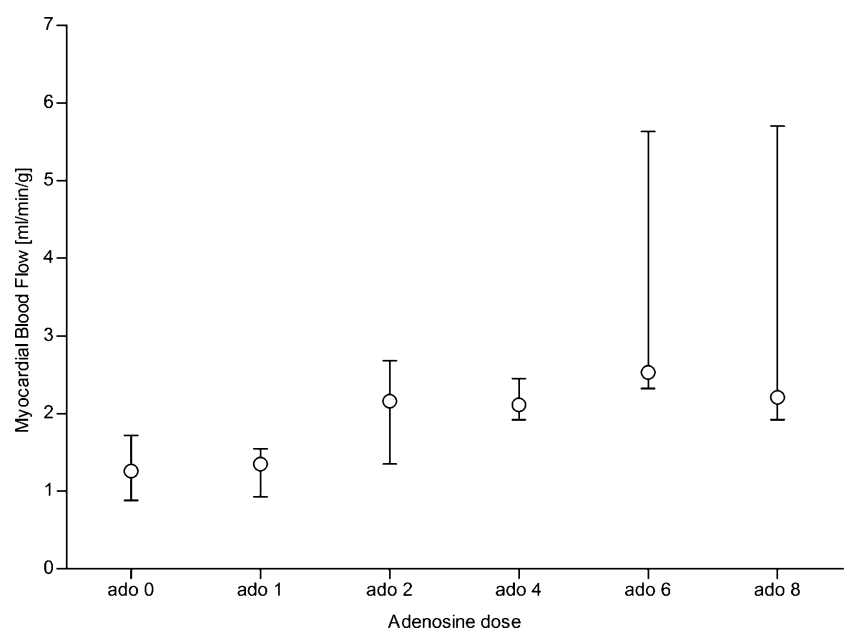

Fig. 2 Myocardial blood flow (median and range) in healthy cats measured at rest (Ado 0 ) and after stimulation by increasing dosages of adenosine infused over 7 minutes (Ado 2-Ado 8). The adenosine dosage is given in relation to the human standard dose (Ado 1) $140 \mu \mathrm{g} / \mathrm{kg} / \mathrm{min}$; Ado $2=$ twice human standard dose, $280 \mu \mathrm{g} / \mathrm{kg} / \mathrm{min}$; Ado $4=560 \mu \mathrm{g} / \mathrm{kg} / \mathrm{min}$, Ado $8=1120 \mu \mathrm{g} / \mathrm{kg} / \mathrm{min}$ 
maximal MBF without causing relevant adverse effects. In our cats MBF first increased with increasing adenosine dose, but at high doses again decreased in some animals. At adenosine rates of 280 (Ado 2) and $560 \mu \mathrm{g} / \mathrm{kg}$ per minute (Ado 4) similar results were obtained, and the increase in MBF was most consistent. At Ado 2 haemodynamic parameters including RPP were unchanged compared to values at rest, thus excluding confounding effects by changes in cardiac work.

There were no serious adverse effects to adenosine noted, even at higher doses. The few side effects including hypotension, AV block, VPCs and waking up from anaesthesia were all mild, of short duration, and immediately reversed at the end of the adenosine infusion. With the exception of waking up from anaesthesia which only occurred at high adenosine doses, the incidence of side effects was not related to the adenosine dose; in several instances cats did exhibit adverse effects at a lower dose, but not at a higher dose. Based on all these findings and considerations, adenosine administration at a rate of $280 \mu \mathrm{g} / \mathrm{kg}$ per minute over 6-7 min is suggested for use as the standard dose for the determination of maximal MBF and to calculate MPR in anaesthetized cats. While this corresponds to twice the standard microgram per kilogram dose used in human studies, it matches the human standard dose when calculated in relation to body surface area in micrograms per metre squared. Studies in cats with HCM will have to show whether this adenosine dose is equally well tolerated in these cats, and whether differences in MBF and MPF can be observed and assessed by PET as compared to healthy cats.

At rest, higher values of MBF were obtained in our anaesthetized cats than in awake humans. With a few exceptions the hyperaemic MBF response was in the range of $1.5-5.0 \mathrm{ml} / \mathrm{min}$ per $\mathrm{g}$ in our healthy anaesthetized cats, which is comparable to the values reported in awake humans $[1,25,26]$ and anaesthetized rats [27, 28]. However, the resulting MPR values ranging between 1.5 and 2.5 were markedly lower than values obtained in awake healthy humans in whom MPR values in the range 2.5-4.0 are generally considered normal. The lower MPR in our anaesthetized cats can mostly be explained by their higher resting MBF. Nevertheless, our results compare well with MPR values reported in anaesthetized rats, in which MPR values range between 1.5 and 2.5 [27]. In two cats we obtained substantially higher MPR values, i.e. 6.4 at Ado 6 and 4.1 at Ado 8. The latter was the cat which woke up repeatedly during infusion of that dose. In the former, heart rate increased markedly from 120 to 189 beats/min, suggesting that this cat also was waking up from anaesthesia. This was reflected by a slight increase in minimal coronary resistance during adenosine infusion at the maximal dose. Thus, the much lower MPR in our study as compared to values found in humans may, at least in part, be attributed to effects of the anaesthesia. Likewise, anaesthesia has been shown to affect MBF in rats [27]. As ethical and feasibility issues demand anaesthesia for measuring MBF by PET in animals but is not ethically justifiable nor technically needed in humans, direct comparison of measurements between animal and human studies are precluded. A further limitation has to be acknowledged with regard to the technical equipment. The scanner used was suited to clinical use and the transaxial resolution was around $6 \mathrm{~mm}$; the left ventricular wall of the cat may reach $5.5-6 \mathrm{~mm}$ with a heart rate twice that in humans. In order to allow for these limitations we used partial volume and spillover correction as mentioned above. We did not perform simultaneous measurements of MBF with another method such as radiolabelled or stable isotopically labelled microspheres to confirm the PET measurements.

\section{Conclusion}

MBF can be measured by PET in anaesthetized cats using ${ }^{13} \mathrm{NH}_{3}$ and our results suggest the use of adenosine at a rate of $280 \mu \mathrm{g} / \mathrm{kg}$ per minute over 6-7 min. Future studies will have to determine the value of measuring MBF by PET for identifying abnormal coronary perfusion in cats with HCM, for identifying different degrees of HCM in cats, and potentially for identifying early and subclinically affected animals without echocardiographically detectable morphological abnormalities.

Acknowledgments We would like to thank Ratko Milovanovic for data acquisition, Sabine B.R. Kaestner for help with planning and monitoring anaesthesia, Claudia E. Reusch for helpful discussions, Stefan Schellenberg for excellent support in preparing the manuscript, and Ingrid Vitali for providing the Maine Coon cats. The study was supported by a grant from the Swiss National Science Foundation (SNSF professorship grant no PP00A-114706).

This work was presented in part at the 15th European College of Veterinary Internal Medicine Companion Animal Congress, Glasgow, UK, 1-3 September 2005.

\section{References}

1. Kaufmann PA, Gnecchi-Ruscone T, Yap JT, Rimoldi O, Camici PG. Assessment of the reproducibility of baseline and hyperemic myocardial blood flow measurements with 15O-labeled water and PET. J Nucl Med 1999;40:1848-56.

2. Wyss CA, Koepfli P, Fretz G, Seebauer M, Schirlo C, Kaufmann PA. Influence of altitude exposure on coronary flow reserve. Circulation 2003;108:1202-7.

3. Jagathesan R, Kaufmann PA, Rosen SD, Rimoldi OE, Turkeimer F, Foale R, et al. Assessment of the long-term reproducibility of baseline and dobutamine-induced myocardial blood flow in patients with stable coronary artery disease. J Nucl Med 2005; 46:212-19. 
4. Siegrist PT, Gaemperli O, Koepfli P, Schepis T, Namdar M, Valenta I, et al. Repeatability of cold pressor test-induced flow increase assessed with $\mathrm{H} 215 \mathrm{O}$ and PET. J Nucl Med 2006; 47:1420-26.

5. Kaufmann PA, Camici PG. Myocardial blood flow measurement by PET: technical aspects and clinical applications. J Nucl Med 2005;46:75-88.

6. Uren NG, Crake T, Lefroy DC, de Silva R, Davies GJ, Maseri A. Delayed recovery of coronary resistive vessel function after coronary angioplasty. J Am Coll Cardiol 1993;21:612-21.

7. Camici P, Chiriatti G, Lorenzoni R, Bellina RC, Gistri R, Italiani G, et al. Coronary vasodilation is impaired in both hypertrophied and nonhypertrophied myocardium of patients with hypertrophic cardiomyopathy: a study with nitrogen-13 ammonia and positron emission tomography. J Am Coll Cardiol 1991;17:879-86.

8. Dayanikli F, Grambow D, Muzik O, Mosca L, Rubenfire M, Schwaiger M. Early detection of abnormal coronary flow reserve in asymptomatic men at high risk for coronary artery disease using positron emission tomography. Circulation 1994;90:808-17.

9. Kaufmann PA, Gnecchi-Ruscone T, di Terlizzi M, Schafers KP, Luscher TF, Camici PG. Coronary heart disease in smokers: vitamin $\mathrm{C}$ restores coronary microcirculatory function. Circulation 2000;102:1233-8.

10. Kaufmann PA, Gnecchi-Ruscone T, Schafers KP, Luscher TF, Camici PG. Low density lipoprotein cholesterol and coronary microvascular dysfunction in hypercholesterolemia. J Am Coll Cardiol 2000;36:103-9.

11. Jenni R, Wyss CA, Oechslin EN, Kaufmann PA. Isolated ventricular noncompaction is associated with coronary microcirculatory dysfunction. J Am Coll Cardiol 2002;39:450-4.

12. Cecchi F, Olivotto I, Gistri R, Lorenzoni R, Chiriatti G, Camici PG. Coronary microvascular dysfunction and prognosis in hypertrophic cardiomyopathy. N Engl J Med 2003;349:1027-35.

13. Jorg-Ciopor M, Namdar M, Turina J, Jenni R, Schwitter J, Turina $\mathrm{M}$, et al. Regional myocardial ischemia in hypertrophic cardiomyopathy: impact of myectomy. J Thorac Cardiovasc Surg 2004;128:163-9.

14. Maron BJ. Hypertrophic cardiomyopathy. Lancet 1997;350:127-33.

15. Meurs KM, Sanchez X, David RM, Bowles NE, Towbin JA, Reiser PJ, et al. A cardiac myosin binding protein $\mathrm{C}$ mutation in the Maine Coon cat with familial hypertrophic cardiomyopathy. Hum Mol Genet 2005;14:3587-93.

16. Meurs KM, Norgard MM, Ederer MM, Hendrix KP, Kittleson MD. A substitution mutation in the myosin binding protein $\mathrm{C}$ gene in ragdoll hypertrophic cardiomyopathy. Genomics 2007;90:261-4.

17. Kittleson MD, Meurs KM, Munro MJ, Kittleson JA, Liu SK, Pion PD, et al. Familial hypertrophic cardiomyopathy in maine coon cats: an animal model of human disease. Circulation 1999;99:3172-80.
18. Weissel M, Brugger G, Raberger G, Kraupp O. The effects of adenosine on coronary conductance, cardiac dynamics and myocardial metabolism of the isolated perfused cat heart. Pharmacology 1974;12:120-8.

19. Breisch EA, Houser SR, Carey RA, Spann JF, Bove AA. Myocardial blood flow and capillary density in chronic pressure overload of the feline left ventricle. Cardiovasc Res 1980;14: 469-75.

20. Koepfli P, Hany TF, Wyss CA, Namdar M, Burger C, Konstantinidis $\mathrm{AV}$, et al. $\mathrm{CT}$ attenuation correction for myocardial perfusion quantification using a PET/CT hybrid scanner. J Nucl Med 2004;45:537-42.

21. Muzik O, Beanlands RS, Hutchins GD, Mangner TJ, Nguyen N, Schwaiger M. Validation of nitrogen-13-ammonia tracer kinetic model for quantification of myocardial blood flow using PET. J Nucl Med 1993;34:83-91.

22. Koepfli P, Wyss CA, Namdar M, Klainguti M, von Schulthess GK, Lüscher TF, et al. Beta-adrenergic blockade and myocardial perfusion in coronary artery disease: differential effects in stenotic versus remote myocardial segments. J Nucl Med 2004;45: $1626-31$.

23. Hutchins GD, Schwaiger M, Rosenspire KC, Krivokapich J, Schelbert H, Kuhl DE. Noninvasive quantification of regional blood flow in the human heart using N-13 ammonia and dynamic positron emission tomographic imaging. J Am Coll Cardiol 1990; $15: 1032-42$.

24. Hutchins GD, Caraher JM, Raylman RR. A region of interest strategy for minimizing resolution distortions in quantitative myocardial PET studies. J Nucl Med 1992;33:1243-50.

25. Wyss CA, Koepfli P, Mikolajczyk K, Burger C, von Schulthess GK, Kaufmann PA. Bicycle exercise stress in PET for assessment of coronary flow reserve: repeatability and comparison with adenosine stress. J Nucl Med 2003;44:146-54.

26. Chareonthaitawee P, Kaufmann PA, Rimoldi O, Camici PG. Heterogeneity of resting and hyperemic myocardial blood flow in healthy humans. Cardiovasc Res 2001;50:151-61.

27. Croteau E, Benard F, Bentourkia M, Rousseau J, Paquette M, Lecomte R. Quantitative myocardial perfusion and coronary reserve in rats with $13 \mathrm{~N}$-ammonia and small animal PET: impact of anesthesia and pharmacologic stress agents. J Nucl Med 2004;45:1924-30.

28. Herrero P, Kim J, Sharp TL, Engelbach JA, Lewis JS, Gropler RJ, et al. Assessment of myocardial blood flow using 15O-water and 1-11C-acetate in rats with small-animal PET. J Nucl Med 2006; 47:477-85.

29. Hodgson DS, Dunlop CI, Chapman PL, Grandy JL. Cardiopulmonary effects of anesthesia induced and maintained with isoflurane in cats. Am J Vet Res Med 1998;59:182-5. 